\title{
The Benefits of Percutaneous Transhepatic Gallbladder Drainage prior to Laparoscopic Cholecystectomy for Acute Cholecystitis
}

\author{
Byeonghun Oh, M.D., Eunyoung Kim, M.D., Eun Jeong Ahn, M.D., Ph.D., Jong-Min Park, M.D., Sei-Hyeog Park, M.D. \\ Department of Surgery, National Medical Center, Seoul, Korea
}

\begin{abstract}
Purpose: Several studies have reported that laparoscopic cholecystectomy with percutaneous transhepatic gallbladder drainage (PTGBD) is associated with a reduced duration of surgery and a lower rate of conversion to open laparotomy compared with laparoscopic cholecystectomy without PTGBD and delayed laparoscopic cholecystectomy after conservative therapy. However, these results are contradictory. This retrospective study investigated the safety and usefulness of laparoscopic cholecystectomy combined with pre-operative PTGBD in patients with acute cholecystitis.
\end{abstract}

Methods: The clinicopathologic data and surgical outcomes of 101 patients who underwent laparoscopic cholecystectomy between January 2010 and September 2015 were reviewed retrospectively.

Results: Patients in the PTGBD group vs. the non-PTGBD group were significantly older (mean age: $65.47 \pm 12.2$ vs. $56.32 \pm 13.7 ; p=0.001$ ). Underlying diseases were also significantly more common in the PTGBD group (75.4\% vs. $45.5 \%$; $p=0.002$ ). There were no significant differences between the two groups in terms of operative time, blood loss, rate of open conversion, postoperative oral intake, and postoperative hospital stay. Total hospital day was significantly longer in the PTGBD group (11.14 \pm 7.22 vs. $6.23 \pm 5.17 ; p=0.049)$. There was no significant difference in the postoperative complications between the two groups, and all patients in this study lived.

Conclusion: This study suggested that satisfactory results can be achieved with selective preoperative PTGBD in older and sicker patients with acute cholecystitis.

Keywords: Acute cholecystitis, Laparoscopic cholecystectomy, Percutaneous transhepatic gallbladder drainage (PTGBD)

This is an Open Access article distributed under the terms of the Creative Commons Attribution Non-Commercial License (http:/ creativecommons.org/licenses/by-nc/4.0/) which permits unrestricted non-commercial use, distribution, and reproduction in any medium, provided the original work is properly cited.
Received December 1, 2015

Revised January 5, 2016

Accepted February 15, 2016

Corresponding author

Sei-Hyeog Park

Department of Surgery, National

Medical Center, Euljiro 6-ga, Jung-

gu, Seoul 04564, Korea

Tel: +82-2-2260-7114

Fax: +82-2-2269-0750

E-mail: spark479@unitel.co.kr

\section{INTRODUCTION}

In recent years, laparoscopic cholecystectomy for nonacute cholecystitis has been widely accepted as a safe and feasible procedure due to the development of improved surgical techniques and devices. However, its applicability for acute cholecystitis remains controversial. $^{1-4}$ The safety, $3,5,6$ and the optimal timing of laparoscopic cholecystectomy $y^{1-3,7}$ have been studied; generally, the outcomes have been good when lapa- roscopic cholecystectomy is carried out early. ${ }^{1-5}$ In addition, several studies have evaluated laparoscopic cholecystectomy after selective sustained percutaneous transhepatic gallbladder drainage (PTGBD) for the control of severe inflammation, ${ }^{3,8-10}$ and improvement of cholecystitis-induced disorders. Especially, Chikamori et al. ${ }^{11}$ reported on 16 laparoscopic cholecystectomy patients with PTGBD who experienced a reduced duration of surgery and a lower rate of conversion to open laparotomy compared with laparoscopic cholecystectomy pa- 
tients who did not receive PTGBD and also those who underwent delayed laparoscopic cholecystectomy after conservative therapy. However, these studies were relatively small, and the results were contradictory. Therefore, this retrospective study researched the safety and the usefulness of laparoscopic cholecystectomy combined with pre-operative PTGBD in patients with acute cholecystitis.

\section{MATERIALS AND METHODS}

\section{Patients}

We retrospectively reviewed a database of 101 patients who had been diagnosed with acute cholecystitis and who underwent laparoscopic cholecystectomy between January 2010 and September 2015. All patients were hospitalized via the emergency room; they were informed about the procedure and gave their consent for surgery.

At our institution, acute cholecystitis is defined by the presence of at least three of the following: (1) right upper abdominal pain, (2) a temperature of $38^{\circ} \mathrm{C}$ or higher, (3) a white blood cell (WBC) count of 10,000/ $\mu 1$ or higher (normal: $4,000 \sim 10,000 / \mu 1$ ), and (4) a gallbladder wall with a thickness of at least $3.5 \mathrm{~mm}$ on transabdominal ultrasound or computed tomography. Patients who required a combined surgery on other organs and also those in whom laparoscopic cholecystectomy was performed for malignant gallbladder disease were excluded. Patients who received conservative therapy (fasting, intravenous fluids, antibiotics) alone also were excluded. In all, 57 patients who underwent PTGBD before undergoing surgery were included in this study. Laparoscopic cholecystectomy was performed as soon as the general condition of the patient was stabile and there was evident improvement in liver function, renal function, respiratory function, cardiac status, blood coagulation parameters, and American Society of Anesthesiologist (ASA) status.

The indications for PTGBD are as follows: (1) severe abdominal symptoms (severe abdominal pain, evidence of peritoneal inflammation) with impaction of stones in the neck of the gallbladder and continuous fever $\left(38^{\circ} \mathrm{C}\right.$ or higher); (2) concomitant jaundice/hepatic dysfunction (total bilirubin $>3.0$ $\mathrm{mg} / \mathrm{dl}$ [total bilirubin; normal: $0 \sim 1.0 \mathrm{mg} / \mathrm{dl}$, and alanine aminotransferase [ALT; normal: 3 40 U/1]/aspartate aminotransferase [AST; normal: 10 35 U/1] >500 U/1), and/or sepsis; and (3) the presence of severe underlying disease.

The characteristics of patients (age, gender, history of abdominal surgery, co-morbidity, etc.), surgical outcomes and postoperative course, which were compared between the PTGBD performance group and the control group (open conversion, operative time, blood loss, postoperative morbidity and mortality, total and postoperative hospital days, postoperative oral intake, patients' sharing of medical cost) were examined.

\section{Surgical techniques}

\section{Percutaneous transhepatic gallbladder drainage (PTGBD)}

PTGBD was performed within 24 hours of admission. After the administration of local anesthesia, an $8.5 \mathrm{~F}$ pigtail catheter (Uresil, Chicago, IL, US) was inserted into the gallbladder under ultrasound guidance via a transhepatic route using the Seldinger technique.

\section{Laparoscopic cholecystectomy}

Patients were placed in the supine position. A nasogastric tube and Foley bladder catheter were placed to decompress these organs and lessen the chance of their injury by the port trocars. The surgeon stood at the left upper side of the patient, and the first assistant was placed across from the surgeon. The scopist was positioned on the right upper side of the patient. After general anesthesia was induced, the camera trocar was inserted using the open access technique in the periumbilical area; pneumoperitoneum was established with the insufflation of carbon dioxide. Intraperitoneal pressure was maintained at 12 13 mmHg. The patient was placed in a mild (20 30 degree) reverse Trendelenbug position by rotating the patient slightly to the left. Three additional trocars were inserted, using direct visualization of their sites of intra-abdominal presentation. The second 12-mm trocar port was placed in the epigastrium about $5 \mathrm{~cm}$ below the xiphoid, with its intra-abdominal entrance site being just to the right of the falciform ligament. Two smaller 5-mm trocar ports for instruments were then placed: one in the right upper quadrant near the midclavicular line several centimeters below the costal margin, and another quite laterally almost at the same level as the umbilicus.

After full inspection of the intra-abdominal cavity, we attempted to expose the cystic duct and artery; these structures were divided with endoscopic heavy scissors after being doubly secured with metal clips both proximally and distally. We grasped the infundibulum of the gallbladder with forceps through the middle port and removed the gallbladder from its bed in a retrograde manner. The gallbladder was removed using an endo-pouch.

\section{Postoperative management}

The nasogastric tube was removed when the patient was alert enough to void, as was the Foley catheter. Pain at the operative site was well controlled with oral medication. Although the patients experienced some transient nausea, most were able to receive oral liquids within one or two days and 
were discharged within three or four days.

\section{Statistical analysis}

All continuous data are presented as the mean \pm standard deviation. Patients' universal characteristics were analyzed using frequency analysis. For a comparison of the two groups, the unpaired t-test was used for numerical data, and the Chisquare test was employed for categorical data, along with the Yates correction for continuity where appropriate. To compare changes in numerical data in the same group, a paired ttest was used as appropriate. A value of $p<0.05$ was regarded as significant. Statistical analyses were performed using the Statistical Package for the Social Sciences (SPSS version 21.0, SPSS, Inc.).

\section{RESULTS}

This study included 101 patients who were diagnosed with acute cholecystitis and underwent laparoscopic cholecystectomy; 58 of these patients met the criteria for PTGBD. Of these, 57 received PTGBD. The remaining patient was unable to undergo the procedure at that time due to the absence of a radiologist and instead required an emergency laparoscopic cholecystectomy the next day. No direct complications of PTGBD were noted. All procedures were carried out at our center by the one surgeon experienced in laparoscopy while patients were under general anesthesia. Patient characteristics are shown in Table 1. The patients were divided into two groups. One group was composed of patients who had PTGBD (PTGBD group). The other was made up of patients without PTGBD (Non-PTGBD group). Patients in the PTGBD group vs. the
non-PTGBD group were significantly older (mean age: $65.47 \pm$ 12.2 vs. $56.32 \pm 13.7$, respectively; $p=0.001$ ). Underlying diseases were significantly more common in the PTGBD group $75.4 \%$ vs. $45.5 \% ; p=0.002)$. There was no significant difference in the gender distribution $(p=0.818)$, history of previous abdominal surgery $(p=0.793)$, or body mass index $(p=0.522)$ between the two groups.

Body temperatures $\left({ }^{\circ} \mathrm{C}\right)$ in the PTGBD group and nonPTGBD groups were $37.39 \pm 0.9$ and $36.90 \pm 0.4(p=0.001)$, re spectively. The WBC counts $\left(10^{3} / \mu 1\right)$ were $15.3 \pm 5.4$ and $13.2 \pm$ $4.0(p=0.0175)$, respectively, while the $C$-reactive protein values $(\mathrm{mg} / \mathrm{d})$ were $74.43 \pm 71.7$ and $39.50 \pm 56.3(\mathrm{P}=0.009)$, respectively. Thus, all of these parameters indicated significantly worse inflammation in the PTGBD group. However, the parameters indicating the general condition of the patients in the PTGBD group substantially improved immediately following PTGBD: the mean body temperature $\left({ }^{\circ} \mathrm{C}\right)$ decreased from $37.39 \pm 0.9$ to $36.68 \pm 0.368(p<0.0001)$, the mean WBC counts $\left(10^{3} / \mu 1\right)$ fell from $15.3 \pm 5.4$ to $7.9 \pm 1.5(p<0.0001)$, and the number of abnormal biochemical parameters decreased from $3.0 \pm 1.9$ to $1.3 \pm 1.1(p<0.0001)$. Because the general conditions of the PTGBD group were better, the mean ASA classification for the PTGBD group also improved from $2.30 \pm 0.5$ to $2.07 \pm 0.6$ $(p<0.0144)$. Before surgery, the respective ASA classifications were $2.07 \pm 0.6$ in the PTGBD group and $1.89 \pm 0.8$ in the nonPTGBD group, a difference that was not significant $(p=0.173)$. The underlying diseases in both the PTGBD group and the non-PTGBD group are shown in Table 2.

Surgical outcomes and postoperative courses are summarized in Table 3. There were no significant differences between the two groups in terms of operative time, blood loss, the rate of open conversion, postoperative oral intake, postoperative

Table 1. Characteristics of patients

\begin{tabular}{|c|c|c|c|c|}
\hline & & $\begin{array}{c}\text { Non-PTGBD } \\
\mathrm{N}=44\end{array}$ & $\begin{array}{l}\text { PTGBD } \\
N=57\end{array}$ & $p$ value \\
\hline Age (year) & Mean \pm S.D & $56.32 \pm 13.7$ & $65.47 \pm 12.2$ & $0.001^{*}$ \\
\hline Gender & $M: F$ & $28: 16$ & $35: 22$ & 0.818 \\
\hline Underlying_diseases $(\%)$ & & $20(45.5)$ & $43(75.4)$ & $0.002^{*}$ \\
\hline Previous abdominal surgery (\%) & & $7(15.9)$ & $8(14.0)$ & 0.793 \\
\hline Body mass index & Mean \pm S.D & $24.09 \pm 4.0$ & $24.65 \pm 4.6$ & 0.522 \\
\hline ASA score & Mean \pm S.D & $1.89 \pm 0.8$ & $2.07 \pm 0.6$ & 0.173 \\
\hline Body temperature $\left({ }^{\circ} \mathrm{C}\right)$ & Mean \pm S.D & $36.90 \pm 0.4$ & $37.39 \pm 0.9$ & $0.001^{*}$ \\
\hline White blood cell count $\left(10^{3} / \mu l\right)$ & Mean \pm S.D & $15.3 \pm 5.4$ & $13.2 \pm 4.0$ & $0.0175^{*}$ \\
\hline CRP (mg/dl) & Mean \pm S.D & $39.50 \pm 56.3$ & $74.43 \pm 71.7$ & $0.009 *$ \\
\hline
\end{tabular}

ASA $=$ American Society of Anesthesiologist; $C R P=C$-reactive protein. ${ }^{*} p$ value $<0.05$. 
Table 2. Underlying diseases

\begin{tabular}{|c|c|c|c|c|}
\hline & & $\begin{array}{c}\text { PTGBD } \\
N=57\end{array}$ & $\begin{array}{l}\text { Non-PTGBD } \\
\qquad \mathrm{N}=44\end{array}$ & Total \\
\hline \multirow[t]{4}{*}{ Cardiac disease } & Heart failure & 2 & & 2 \\
\hline & Atrial fibrillation & 1 & 1 & 2 \\
\hline & Angina & 2 & & 2 \\
\hline & Hypertension & 24 & 12 & 36 \\
\hline \multirow[t]{3}{*}{ Pulmonary disease } & Asthma & 2 & & 2 \\
\hline & COPD & 3 & 2 & 5 \\
\hline & Old tuberculosis & & 1 & 1 \\
\hline \multirow[t]{11}{*}{ Gastrointestinal disease } & Liver cirrhosis & 1 & & 1 \\
\hline & Hepatocellular carcinoma & 1 & & 1 \\
\hline & Hepatitis type B & 4 & 1 & 5 \\
\hline & Hepatitis type C & 1 & 1 & 2 \\
\hline & Intestinal obstruction & 1 & 1 & 2 \\
\hline & Sigmoid colon cancer. & & 1 & 1 \\
\hline & Pancreatitis & 1 & & 1 \\
\hline & Stomach cancer. & 1 & 1 & 2 \\
\hline & Gastric ulcer & 1 & 1 & 2 \\
\hline & Gastric ulcer perforation & & 1 & 1 \\
\hline & Acute appendicitis & 4 & 2 & 6 \\
\hline \multirow[t]{3}{*}{ Endocrine disease } & Diabetes mellitus & 13 & 3 & 16 \\
\hline & Hyperthyroidism & 1 & & 1 \\
\hline & Hypothyroidism & & 1 & 1 \\
\hline \multirow[t]{2}{*}{ Vascular disease } & Cerebral infarction & 2 & 1 & 3 \\
\hline & Internal carotid artery stenosis & 1 & & 1 \\
\hline \multirow[t]{2}{*}{ Infective disease } & Syphillis & 1 & 1 & 2 \\
\hline & AIDS & 1 & & 1 \\
\hline Renal disease & Chronic kidney disease & 1 & 1 & 2 \\
\hline Psychiatric disease & Dementia & 3 & & 3 \\
\hline Total & & 72 & 32 & 104 \\
\hline
\end{tabular}

$\mathrm{COPD}=$ Chronic obstructive pulmonary disease; $\mathrm{AIDS}=$ Acquired immune deficiency syndrome.

hospital stay, patients' sharing of medical cost. But, Total hospital day was significantly longer in the PTGBD group (11.14 \pm 7.22 vs. $6.23 \pm 5.17 ; p=0.049$ ). We were unable to identify any significant difference of postoperative complications between the two groups. No patients died during this study.

Complications in the PTGBD group included the following: bile leak (1 patient), biliary sepsis (1), pleural effusion (2), pneumonia (2), postoperative ileus (1), and postoperative bleeding (1). Complications in the non-PTGBD group were as follows: oliguria (1 patient), pleural effusion (1), and infection of the surgical wound (1) (Table 4). The reasons for conversion to open surgery were Mirrizi's syndrome in two patients, fibrosis of Calot's triangle in one patient, gallbladder wall bleeding in one patient, and common bile duct injury in one patient in the PTGBD group. In the non-PTGBD group, the reasons were Mirrizi's syndrome in two patients, fibrosis 
Table 3. Surgical outcomes and postoperative courses

\begin{tabular}{|c|c|c|c|c|}
\hline & & $\begin{array}{c}\text { PTGBD } \\
N=57\end{array}$ & $\begin{array}{c}\text { Non-PTGBD } \\
\mathrm{N}=44\end{array}$ & $p$ value \\
\hline Operative time (min) & Mean \pm S.D & $100.23 \pm 30.8$ & $95.36 \pm 36.8$ & 0.472 \\
\hline Blood loss (ml) & Mean \pm S.D & $44.49 \pm 88.8$ & $41.41 \pm 67.8$ & 0.849 \\
\hline Open conversion $(\%)$ & & $5(8.8)$ & $4(9.1)$ & 0.956 \\
\hline Postoperative oral intake (days) & Mean \pm S.D & $2.86 \pm 3.4$ & $2.39 \pm 1.5$ & 0.393 \\
\hline Postoperative morbidity $(\%)$ & & $8(14.0)$ & $3(6.8)$ & 0.248 \\
\hline Postoperative mortality (\%) & & $0(0)$ & $0(0)$ & - \\
\hline Total hospital stay (days) & Mean \pm S.D & $11.14 \pm 7.22$ & $6.23 \pm 5.17$ & $0.049^{*}$ \\
\hline Postoperative hospital stay (days) & Mean \pm S.D & $4.26 \pm 7.28$ & $4.16 \pm 6.51$ & 0.941 \\
\hline Patients' sharing of medical cost (won) & Mean \pm S.D & $2,176,298 \pm 1,134,477$ & $1,767,522 \pm 1,280,912$ & 0.093 \\
\hline
\end{tabular}

${ }^{*} p$ value $<0.05$.

Table 4. Postoperative morbidity

\begin{tabular}{|lccc}
\hline & $\begin{array}{c}\text { PTGBD } \\
\mathbf{N}=\mathbf{5 7}\end{array}$ & $\begin{array}{c}\text { Non-PTGBD } \\
\mathbf{N = 4 4}\end{array}$ & p vlaue \\
\hline Bile leakage & 1 & 0 & \\
\hline Biliary sepsis & 1 & 0 & \\
\hline Oliguria & 0 & 1 & \\
\hline Pleural effusion & 2 & 1 & \\
\hline Pneumonia & 2 & 0 & \\
\hline Postoperative ileus & 1 & 0 & \\
\hline Postoperative bleeding & 1 & 0 & \\
\hline Wound infection & 0 & 1 & \\
\hline Total & 8 & 3 & 0.248 \\
\hline
\end{tabular}

of Calot's triangle in one patient, and gallbladder bleeding in one patient (Table 5). Postoperatively, all patients experienced complete resolution of their symptoms $(100 \%$ overall response to laparoscopic cholecystectomy).

\section{DISCUSSION}

When laparoscopic cholecystectomy was first developed, acute cholecystitis was considered a contraindication for the procedure. ${ }^{12,13}$ However, with the development of greater technical skills and superior laparoscopic instruments, the number of surgical teams that apply laparoscopic cholecystectomy first in acute cholecystitis patients is increasing. While laparoscopic cholecystectomy has gained a leading role in the treatment of acute cholecystitis despite its reportedly high rates of conversion to open surgery, the optimal timing for laparoscopic
Table 5. Reasons for open conversion

\begin{tabular}{|c|c|c|c|}
\hline PTGBD (N=57) & & \multicolumn{2}{|l|}{ Non-PTGBD (N=44) } \\
\hline \multicolumn{2}{|c|}{ Total number of patients = 5} & \multicolumn{2}{|c|}{ Total number of patients = 4} \\
\hline Mirrizi's syndorome & 2 & Mirrizi's syndorome & 2 \\
\hline Fibrosis of Calot's triangle & 1 & Fibrosis of Calot's triangle & 1 \\
\hline Gallbladder wall bleeding & 1 & Gallbladder wall bleeding & 1 \\
\hline Common bile duct injury & 1 & & \\
\hline
\end{tabular}

cholecystectomy in patients with acute cholecystitis has been a matter of controversy during the few past decades. ${ }^{14}$ Most surgeons agree that the timing of the procedure is an important factor in determining the patient's treatment outcome. The surgery should ideally be performed as soon as possible. Although operation within 72 hours of symptom onset has been suggested, ${ }^{1,2,7}$ such early surgery is not always possible in clinical practice due to logistic difficulties in performing surgery on these patients on an emergent basis. Moreover, emergency surgical procedures sometimes cause serious complications in high-risk patients and cannot be performed in all hospitals. The selection of early surgical timing forces hemodynamically unstable patients to undergo surgery while they are still in poor general condition.

Some studies have emphasized the safety and the usefulness of laparoscopic cholecystectomy combined with preoperative PTGBD in patients with acute cholecystitis. Chikamori et al. ${ }^{11}$ reported that 16 laparoscopic cholecystectomy patients with PTGBD experienced a reduced duration of surgery and a lower rate of conversion to open laparotomy compared with those who received either laparoscopic cholecystectomy without PTGBD or delayed laparoscopic cholecystectomy after con- 
servative therapy.

Patients who underwent PTGBD in this study were older and were therefore more likely to have comorbid disease compared with the group that did not undergo PTGBD. Moreover, the PTGBD group had more severe acute cholecystitis, as determined by the presence of fever, an elevated WBC count, and a raised $\mathrm{C}$-reactive protein level; they also had more cholecystitis-induced disorders that could be classified as severe. Thus, elderly patients who had more general risk factors and were at an increased surgical risk, as well as those with acute cholecystitis of a greater severity, were selected for PTGBD. Spira et al. ${ }^{13}$ categorized severe cholecystitis-induced symptoms and advanced age as indications for PTGBD prior to laparoscopic cholecystectomy. Interestingly, the average body temperature $\left({ }^{\circ} \mathrm{C}\right)$ was $37.39 \pm 0.9$ in the PTGBD group and $36.90 \pm 0.4$ in the non-PTGBD group ( $p=0.001$ ). The mean body temperature of each group therefore did not indicate a high fever, which would have been over $38^{\circ} \mathrm{C}$. Because many patients who feel upper abdominal pain or chills may take over-the-counter medications to relieve these symptoms before visiting the hospital, each group's mean body temperature had a tendency to be low.

Patients who underwent PTGBD experienced an improvement in their general condition. As a result, the preoperative ASA classification in the PTGBD group was not significantly different from that of the non-PTGBD group.

Kim et al. ${ }^{15}$ observed that the duration of surgery was longer in patients who underwent PTGBD followed by delayed laparoscopic cholecystectomy compared with their non-PTGBD group. In contrast, Chikamori et al. ${ }^{11}$ found that the duration of surgery was shortened when laparoscopic cholecystectomy was performed as soon as possible after PTGBD. In our study, the operative time and amount of blood loss were not significantly different between the two groups. If patients in the PTGBD group had not undergone PTGBD, the longer operative time was expected due to their poor conditions. However, the general conditions of patients were improved following PTGBD, which made the operative time in this group similar to that of the non-PTGBD group.

There was no significant difference with regard to the period between the operation and the first oral intake (postoperative oral intake) or the postoperative hospital stay between the PTGBD group and the non-PTGBD group. Feeding was resumed after 2.86 \pm 3.4 days in the PTGBD group and after $2.39 \pm 1.5$ days in the non-PTGBD group, which is consistent with the less-invasive nature of laparoscopic cholecystectomy. However, total hospital day was significantly longer in the PTGBD group (11.14 \pm 7.22 vs. $6.23 \pm 5.17 ; p=0.049)$. Because of taking time to recover their general condition in PTGBD group, total hospital day of PTGBD group became longer than that of non-PTGBD group. On average, it took $5.09 \pm 2.3$ days for patients in PTGBD group to have an operation after undergoing PTGBD procedure.

There was no significant difference concerning the patients' sharing of medical cost between the PTGBD group and the non-PTGBD group $(2,176,298 \pm 1,134,477$ vs. $1,767,522 \pm$ $1,280,912 ; p=0.093)$. Therefore, PTGBD is a useful procedure and patients who have poor conditions will expect an improvement in their general condition through PTGBD without great expense of medical cost.

The reported complication rate associated with laparoscopic cholecystectomy performed for acute cholecystitis ranges from $10.8 \%$ to $15.3 \%{ }^{1-4,8}$ The complication rates in the PTGBD group and non-PTGBD groups in this study were $14.0 \%$ and $6.8 \%$, respectively. The rate of conversion to open surgery in the studies of Texeira et al., ${ }^{8}$ Eldar et al., ${ }^{3}$ Lai et al., ${ }^{2}$ and Suter and Meyer $^{4}$ were relatively high $(24 \%, 28.5 \%, 22 \%$, and $15.6 \%$, respectively). In the present study, the conversion rate was $8.8 \%$ in the PTGBD group and $9.1 \%$ in the non-PTGBD group, a difference that was not significant $(p=0.956)$. These rates were lower than those of prior studies. When laparoscopic cholecystectomy is performed for severe cholecystitis, the rate of conversion to open surgery generally is high; thus, PTGBD may have decreased the conversion rate in the present study.

It is important to recognize several limitations in this study. First, the number of cases was small. Therefore, multicenter participation will be necessary to extract a better outcome. Second, long-term results were limited due to loss to followup. Third, a cost analysis was affected by policies of national health insurance, patients' social state, patients' underlying diseases and etc. very much. Fourth, this report may have errors common in retrospective studies. Therefore, these limitations might have influenced the outcomes.

Despite these limitations, PTGBD is recommended for patients with severe abdominal symptoms caused by gallbladder inflammation, with hepatic dysfunction or sepsis, and with severe comorbid diseases. When PTGBD is performed in patients with severe acute cholecystitis and severe comorbid disease, it buys some time until laparoscopic cholecystectomy can be safely and feasibly carried out. However, the longer laparoscopic cholecystectomy is delayed after admission, the bigger and denser the fibrosis and adhesions will be. Therefore, laparoscopic cholecystectomy should be performed as soon as the patient's ASA status improves following PTGBD.

\section{REFERENCES}

1) Lo CM, Liu CL, Fan ST, Lai EC, Wong J. Prospective randomized study of early versus delayed laparoscopic cholecystectomy for acute cholecystitis. Ann Surg 1998;227:461-467. 
2) Lai PB, Kwong KH, Leung KL, et al. Randomized trial of early versus delayed laparoscopic cholecystectomy for acute cholecystitis. Br J Surg 1998;85:764-767.

3) Eldar S, Eitan A, Bickel A, et al. The impact of patient delay and physician delay on the outcome of laparoscopic cholecystectomy for acute cholecystitis. Am J Surg 1999;178:303-307.

4) Suter M, Meyer A. A 10-year experience with the use of laparoscopic cholecystectomy for acute cholecystitis: is it safe? Surg Endosc 2001;15:1187-1192.

5) Kum CK, Eypasch E, Lefering R, Paul A, Neugebauer E, Troidl H. Laparoscopic cholecystectomy for acute cholecystitis: is it really safe? World J Surg 1996;20:43-48; discussion 48-49.

6) Lujan JA, Parrilla P, Robles R, Marin P, Torralba JA, GarciaAyllon J. Laparoscopic cholecystectomy vs open cholecystectomy in the treatment of acute cholecystitis: a prospective study. Arch Surg 1998;133:173-175.

7) Chandler CF, Lane JS, Ferguson P, Thompson JE, Ashley SW. Prospective evaluation of early versus delayed laparoscopic cholecystectomy for treatment of acute cholecystitis. Am Surg 2000;66: 896-900.

8) Teixeira JP, Saraiva AC, Cabral AC, Barros H, Reis JR, Teixeira A. Conversion factors in laparoscopic cholecystectomy for acute cholecystitis. Hepatogastroenterology 2000;47:626-630.
9) Kiviluoto T, Siren J, Luukkonen P, Kivilaakso E. Randomised trial of laparoscopic versus open cholecystectomy for acute and gangrenous cholecystitis. Lancet 1998;351:321-325.

10) Eldar S, Sabo E, Nash E, Abrahamson J, Matter I. Laparoscopic cholecystectomy for acute cholecystitis: prospective trial. World J Surg 1997;21:540-545.

11) Chikamori F, Kuniyoshi N, Shibuya S, Takase Y. Early scheduled laparoscopic cholecystectomy following percutaneous transhepatic gallbladder drainage for patients with acute cholecystitis. Surg Endosc 2002;16:1704-1707.

12) Graves HA Jr, Ballinger JF, Anderson WJ. Appraisal of laparoscopic cholecystectomy. Ann Surg 1991;213:655-662; discussion 662-654.

13) Schirmer BD, Edge SB, Dix J, Hyser MJ, Hanks JB, Jones RS. Laparoscopic cholecystectomy. Treatment of choice for symptomatic cholelithiasis. Ann Surg 1991;213:665-676; discussion 677.

14) Germanos S, Gourgiotis S, Kocher HM. Clinical update: early surgery for acute cholecystitis. Lancet 2007;369:1774-1776.

15) Kim KH, Sung CK, Park BK, Kim WK, Oh CW, Kim KS. Percutaneous gallbladder drainage for delayed laparoscopic cholecystectomy in patients with acute cholecystitis. Am J Surg 2000;179:111113. 